\title{
The Use of the PCR-Based Dot-Blot Hybridization Assay to Detect Resistance Markers to Rifampicin and Streptomycin in Mycobacterium tuberculosis Isolates from the SW Region of Cameroon
}

\author{
Irene Ane-Anyangwe ${ }^{1}$, Wilfred Fon Mbacham ${ }^{2}$, Henry Dilonga Meriki ${ }^{3}$, Teyim Pride ${ }^{1,2}$, \\ Theresa Nkuo-Akenji' ${ }^{1}$, Veronique Mbeng Penlap², Leopold Djomkam Tietcheu2, \\ Damian Nota Anong1, Akindeh Mbuh Nji², Vincent P. K. Titanji ${ }^{1}$ \\ ${ }^{1}$ Department of Biochemistry and Microbiology, Faculty of Science, University of Buea, Buea, Cameroon \\ ${ }^{2}$ Laboratory for Public Health Research Biotechnologies, Biotechnology Centre, University of Yaoundé, \\ Yaoundé, Cameroon \\ ${ }^{3}$ Mezam Polyclinic, Bamenda, Cameroon \\ Email: *ianyangwe@yahoo.com
}

Received 16 March 2016; accepted 4 June 2016; published 7 June 2016

Copyright @ 2016 by authors and Scientific Research Publishing Inc.

This work is licensed under the Creative Commons Attribution International License (CC BY).

http://creativecommons.org/licenses/by/4.0/

(c) (i)

\section{Abstract}

Drug sensitivity testing to establish resistance to TB drugs takes many months to arrive at. Public health physicians have difficulties with such an approach due to long wait periods and cannot use it to establish community wide prevalence as a way to understand where resistance may be emerging faster and to limit its spread. The objective of this study was to use the dot-blot hybridization technique in the detection of resistance to rifamycin (RIF) and streptomycin (SM) in SouthWestern Cameroon and to compare the technique with the routine culture and drug susceptibility testing for detecting resistance in a resource poor country, Cameroon. A hospital-based study was conducted at the Regional hospitals of Buea and Limbe and Tiko Central Clinic. Tuberculosis (TB) patients aged 15 to 50 (mean age: $30.50 \pm 8.33$ standard deviation) were recruited for the study between December 2006 and April 2007. Cultures from 59 patients were tested for rifampicin and streptomycin sensitivity by the modified proportion method and mutational analysis for rpoB codon 516 and rrs codon 513 was performed by the dot-blot hybridization technique. Of the 59 sputum samples collected ( 36 were males and 23 were females) came from Buea 19 (32.2\%), Limbe

\footnotetext{
${ }^{*}$ Corresponding author.

How to cite this paper: Ane-Anyangwe, I., Mbacham, W.F., Meriki, H.D., Pride, T., Nkuo-Akenji, T., Penlap, V.M., Tietcheu, L.D., Anong, D.N., Nji, A.M. and Titanji, V.P.K. (2016) The Use of the PCR-Based Dot-Blot Hybridization Assay to Detect Resistance Markers to Rifampicin and Streptomycin in Mycobacterium tuberculosis Isolates from the SW Region of Cameroon. Journal of Tuberculosis Research, 4, 72-79. http://dx.doi.org/10.4236/itr.2016.42009
} 
$20(33.9 \%)$ and Tiko 20 (33.9\%) towns respectively. Amplification for the gene showed that there was (59) $100 \%$ amplification with primers used for $r p o B$ genes and $43(72.9 \%)$ amplification with primers used for the rrs gene. Mutational analysis demonstrated that resistance to RIF was common in females $(52.1 \%)$ than males $(41.7 \%)$ while $6 \%$ of the samples were indeterminate. 12 $(20.3 \%)$ samples showed phenotypic and genotypic resistance to RIF compared to 34 samples (58.1\%) for SM. Phenotypic resistance and genotypic susceptibility were found in $5(8.5 \%)$ RIF and $3(4.7 \%)$ SM compared to phenotypic susceptibility and genotypic resistance that were found in $2(3.5 \%)$ RIF and 3(4.7\%) SM. Double mutation on rpoB and rrs genes occurred in $8(13.6 \%)$ DNA samples. Resistance to RIF and SM due to mutations on the rpoB and rrs genes respectively in the SW region was found to be high and comparable to the drug susceptibility testing by $92 \%$, (95\% CI: 75.7 - 99.1). The Dot-blot technique will be useful in rapidly assessing the effectiveness of national TB control programs in limiting the spread of resistance strains in Cameroon.

\section{Keywords}

PCR-Based DOT-Blot Analysis, Rifamycin, Streptomycin, SW Region

\section{Introduction}

Tuberculosis (TB) remains one of the world's most serious problems, causing about 3 million deaths per year. It accounts for about one third of all preventable adult deaths globally [1] [2]. TB will undoubtedly increase in prevalence in most countries due to increasing number of multidrug resistant (MDR) Mycobacterium tuberculosis strains [3] [4] and the Human Immunodeficiency Virus (HIV) pandemic [5]. As such the World Health Organization declared TB to be a global public health emergency [5].

The emergence of multi-drug resistant strains of Mycobacterium tuberculosis, with resistance to at least rifampin (RIF) and isoniazid (INH) is due to particular genomic mutations of Mycobacterium tuberculosis. Ten (10) genes are known to be linked to resistance to the first line antituberculosis drugs. These drugs include $K a t G$, inhA, aphC, kasA and $n d h$ for INH resistance; rpoB for RIF resistance; rps $L$ and rrs for Streptomycin (SM); embB for Ethambutol (EMB) apncA for Pyrazinamid (PZA) resistance. Rifamycin is a key component of the World Health Organization Directly Observed Therapy Scheme ([DOTS], short course) regimen and, since RIF mono-resistance is extremely rare, INH resistance is usually preceded by that of RIF. Resistance to RIF is considered to be the MDR marker [6] and has been shown in studies that RIF resistance of between $95 \%$ - 98\% is caused by mutation in the $r p o B$ gene encoding the RNA Polymerase B-subunit [7] [8]. Sputum smear microscopy has been the most cost effective diagnostic technique used for TB in most developing countries, where culturing is usually impossible. Early diagnosis, effective treatment and successful cessation of transmission are major strategies in the control of TB.

A PCR-based dot-blot hybridization strategy using labeled specific probes has been used to screen for mutation in genes responsible for resistance to drugs [9] [10]. Molecular methods can be used to determine the genetic changes that lead to antibiotics resistance. However, the use of such methods is restricted to well-equipped laboratories. For countries which do routine culture of specimens for Mycobacterium tuberculosis, the ability to type isolates using small amounts of DNA may be of additional valuable. This study aimed at identifying the presence of Drug Resistance (DR) by comparing phenotypic (DST) and genotypic (Dot-blot) results, targeting $r p o B$ and $r$ rs genes.

\section{Methods}

\subsection{Admission Criteria and Informed Consent}

Ethical clearance for this work was obtained from the South West Regional Delegation of Public Health. Following the patient's or guardian's consent, early morning sputa $(0.5-1 \mathrm{~mL})$ were collected. Only participants diagnosed as smear positive pulmonary tuberculosis were enrolled in the study. 


\subsection{Sample Collection}

Sputum samples were collected between December 2006 and April 2007 from 59 TB patients coming from different localities within the South West Region for pulmonary Tuberculosis diagnosis at the Regional hospitals of Buea and Limbe and Tiko Central Clinic. Data on medical history, age, gender, residence, bacterial colony counts were collected. Smears were prepared, stained with Ziehl-Neelsen stain [11] and viewed under a light microscope at $\times 1000$ magnification. The 59 sputum samples for culture were put into $50 \mathrm{ml}$ screw-capped falcon tubes and sent to the Mezam Polyclinic within 24 hours, where culture and phenotypic drug sensitivity testing were carried out.

\subsection{Cultured Sample for DNA Analysis}

Culture and antibiotic susceptibility testing was done as described previously [12]. Specimens were liquefied and decontaminated using N-acetyl-Lcysteine-sodium hydroxide (BD MycoPrep ${ }^{\mathrm{TM}}$, Becton Dickinson Diagnostic System, Maryland, and USA) following manufacturer's instructions [13] and concentrated by centrifugation at $4000 \mathrm{rpm}$ for $15-20$ minutes at room temperature [14]. Samples were inoculated in triplicate on three Lowenstein-Jensen media slants (one supplemented with $0.4 \%$ pyruvate). The cultures were incubated at $37^{\circ} \mathrm{C}$ and examined weekly for a maximum duration of 8 weeks. Identification of isolates as Mycobacterium tuberculosis was by microscopy of Ziehl-Neelsen stained smears, colony morphology, nitrate reduction, niacin accumulation, catalase activity at $25^{\circ} \mathrm{C}$ and $68^{\circ} \mathrm{C}$ [15]. Drug susceptibility testing was performed on LowensteinJensen medium slants by the standard indirect modified proportion method of Canetti et al. [16]. A loop full of the cultured cells was put into a $1.5 \mathrm{~mL}$ micro centrifuge tube for DNA extraction. About $1.0 \mathrm{~mL}$ of sterile distilled water was added and placed in a heating block at $100^{\circ} \mathrm{C}$ for $30 \mathrm{~min}$. The lysate was centrifuged for $2 \mathrm{mi}-$ nutes and the supernatant used for PCR assay according to Nolte et al. [17]. Positive control was achieved with the reference strain H37Rv a well characterized molecular clinical isolate of M. tuberculosis [12]. Distilled water served as negative control.

\subsection{PCR Amplification}

Some $2 \mathrm{uL}$ of genomic DNA was used as template for amplification in a $23 \mathrm{uL}$ reaction mixture consisting each at final concentrations of magnesium chloride $2.5 \mathrm{mM}$; dNTPs $200 \mathrm{Um}$ each, 5' primer and 3' Primer, $0.2 \mathrm{Um}$ and $1.5 \mathrm{U}$ of Taq polymerase (Promega). The reaction was conducted as follows: $93^{\circ} \mathrm{C}$ for 3 minutes followed by 35 cycles at $93^{\circ} \mathrm{C}$ for 1 minute, annealing at Tm for 1 minute and extension step at $72^{\circ} \mathrm{C}$ for 2 minutes. Final extension was done at $72^{\circ} \mathrm{C}$ for 10 minutes. The optimal annealing temperature was $58^{\circ} \mathrm{C}$ for $r p o B$ gene and $64^{\circ} \mathrm{C}$ for $r r s$ gene.

\subsection{Amplification and Dot-Blot Hybridization}

Efficient amplification of PCR product was confirmed by gel electrophoresis on $12 \%$ polyacryamide gel. To verify the possibility of an omission in a gene sequence, a mix-in experiment was performed with $1 \mathrm{ul}$ of each DNA sample that did not amplify in the presence of another gene that did amplify. Oligonucleotides were labeled at the 5 ' end by phosphorylation with [Y-32P] ATP (Amersham) as described previously. ${ }^{18}$ PCR products were heat-denatured at $95^{\circ} \mathrm{C}$ for 10 minutes and applied under vacuum to a Hybond-N+ nylon filter (Amersham) in a dot-blot apparatus (Bio-Rad). The DNA was fixed unto the membrane by baking at $80^{\circ} \mathrm{C}$ for 1 hour. For radio isotopic detection, each filter was hybridized in 5X SSPE buffer and finally washed in $1.5 \times$ SSPE buffer for 10 minutes at $74^{\circ} \mathrm{C}$ as described previously [18]. Autoradiography was done at room temperature for $2-3$ hours [19]. To re-probe, the membrane was stripped by incubation at $46{ }^{\circ} \mathrm{C}$ in $1 \mathrm{M} \mathrm{NaOH}$ and neutralization was carried out according to the method of Victor, et al. [18].

\subsection{Statistical Analysis}

Data analysis was done using Microsoft Excel 2003 and SPSS for Windows version 11.0 (Somers, NY). The Pearson's Chi square test was used to compare qualitative variables. Statistical significance was set at $\mathrm{p} \leq 0.05$. 


\section{Results}

\subsection{Study Population Characteristics}

A total of 59 patients ( 36 males and 23 females) were enrolled in the study. Participants were aged ranging from of 15 to 50 years, mean age: $30.50 \pm 8.33$ standard deviation (SD). Majority of the participants $(42.4 \%)$ were between the ages 21 and 30 years. Nineteen patients (32.2\%) came from Buea, 20 (33.9\%) from Limbe and 20 (33.9\%) from Tiko, which are the three major health areas in Fako Division of South-Western Cameroon (Table 1).

\subsection{Drug Resistance Pattern by Age and Sex}

There was no significant difference in the drug resistance to both drugs with sex ( $\mathrm{p}=0.774$ for RIF) and $(\mathrm{p}=$ 0.778 for SM). However, more females $12 / 23$ (52.1\%) had RIF resistant TB than males $15 / 36(41.7 \%)$, while more males 9/36 (25\%) had SM resistant TB than females 5/23 (21.7\%). No resistance to RIF was found in subjects $\leq 20$ years, while the highest resistance to SM was seen in the age group $21-30(28 \%)$, closely followed by those above 40 years (25\%). The highest resistance to SM was recorded in the age group $21-30$ years (56\%), closely followed by age group $31-40$ years $(43.8 \%)$, and the age group greater than 40 years $(41.7 \%)$ and that less than 20 years $(25 \%)$.

\subsection{Dot-Blot Mutational Analysis}

Figure 1 shows the mix-in experiment used to verify the possibility of an omission in a gene sequence. All 59 $(100 \%)$ amplified with the rpoB primer. Mutations for $r p o B$ genes occurred in $14(23.7 \%)$ of the samples (Table1a). Forty three $(72.9 \%)$ samples amplified with primers specific for the $r r s$ genes (Table 1). Mutation resulting in resistance to streptomycin occurred in $27(62.8 \%)$ of these (Table 1). Mutational analysis for drug resistance could not be performed on the remaining 16 (27.1\%) samples, since they could not amplify with rrs primer.

\subsection{Comparison between Phenotypic and Genotypic Resistances}

Twelve of the 59 samples (20.3\%) showed both resistance to drugs in vitro and carried the mutations that confer resistances to rifamycin (Table 1), while 25 (58.1\%) of the 43 amplified were resistant both by drug susceptibility testing (DST) and by dot-blot to streptomycin (Table 3). Five out of $59(8.5 \%)$ were resistant to rifamycin yet did not bear the mutations that confer resistance to rifamycin (Table 2). Similarly, 2 out of $43(4.7 \%)$ were resistant to phenotypic DST but would not show resistant conferring mutations to streptomycin (Table 3). On the other hand 2 of the $59(3.4 \%)$ bacterial DNA samples showed susceptibility in vitro yet and bore the gene

Table 1. Study participants characteristics.

\begin{tabular}{|c|c|c|}
\hline \multicolumn{2}{|c|}{ Characteristics } & \multirow{2}{*}{$\mathrm{n}(\%)$} \\
\hline & Categories & \\
\hline \multirow[t]{4}{*}{ Age group (years) } & $\leq 20$ & $4(6.8)$ \\
\hline & $21-30$ & $25(42.4)$ \\
\hline & $31-40$ & $18(30.5)$ \\
\hline & $>40$ & $12(20.3)$ \\
\hline \multirow[t]{2}{*}{ Sex } & Male & $36(61.0)$ \\
\hline & Female & $23(39.0)$ \\
\hline \multirow[t]{3}{*}{ Site of Collection } & Tiko & $20(33.9)$ \\
\hline & Buea & $19(32.2)$ \\
\hline & Limbe & $20(33.9)$ \\
\hline
\end{tabular}




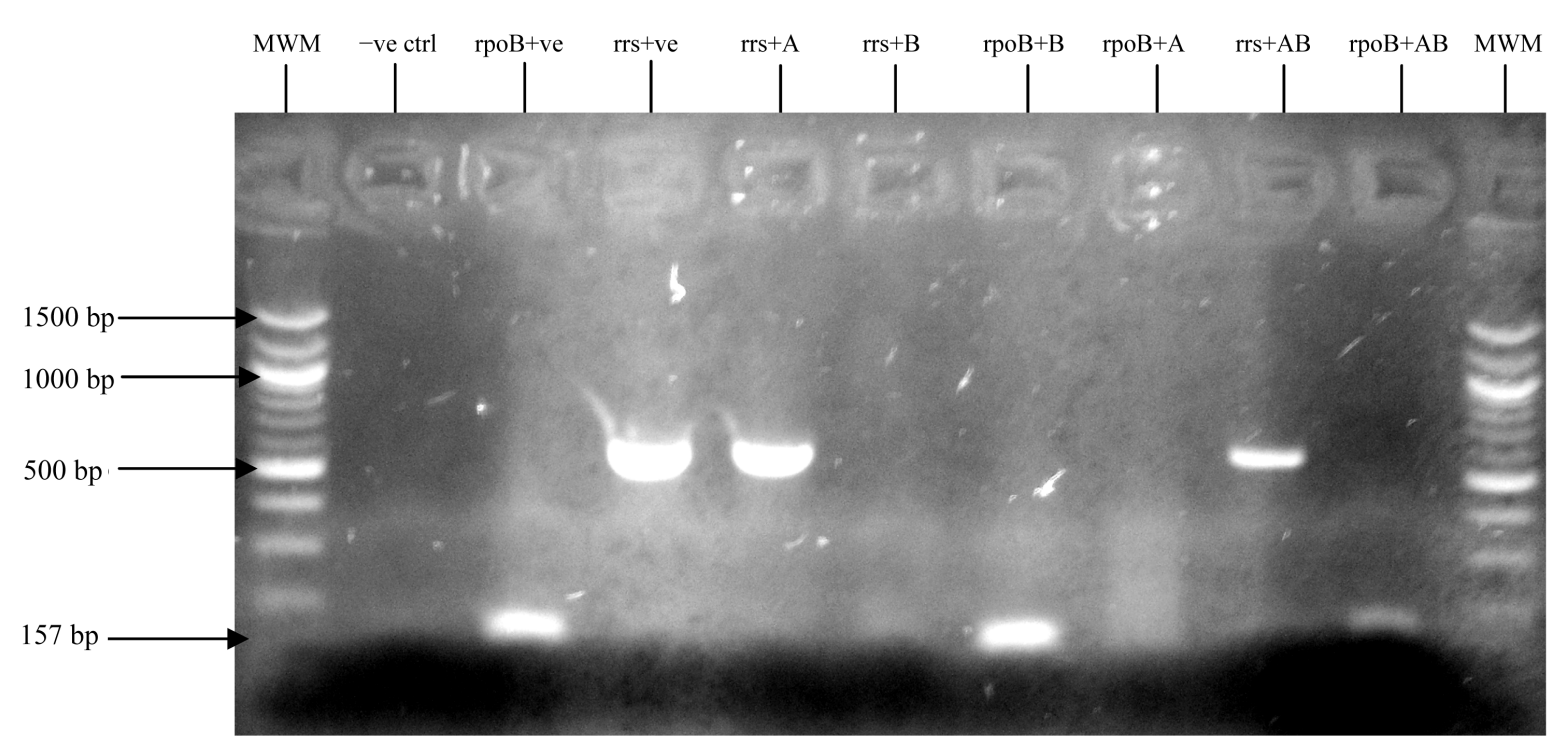

Figure 1. Mix-experiment gel electrphioresis. Mix-in experiment showing the amplified and non-amplified results. Amplification was identified by the presence of band in the wells on the gels. Bands were seen for molecular weight markers, positive controls for the genes rpoB and rrs, sample A was amplified with both rpoB and rrs genes, sample B was amplified only with rpoB gene as primer, and a mixture of $A$ and $B$ were amplified with both rpoB and rrs genes. No amplification identified by the absence of bands was seen for negative control and for sample B with rrs as primer.

Table 2. Comparability between $r p o B$ gene dot-blot and phenotypic drug susceptibility testing.

\begin{tabular}{|c|c|c|c|c|c|c|c|c|}
\hline \multirow{2}{*}{$\begin{array}{c}\text { RIFAMYCIN } \\
\text { (rpoB gene) }\end{array}$} & & \multicolumn{3}{|c|}{ Phenotypic DST, n (\%) } & \multirow{2}{*}{$\begin{array}{c}\% \text { Sensitivity } \\
(95 \% \mathrm{CI})\end{array}$} & \multirow{2}{*}{$\begin{array}{c}\% \text { specificity } \\
(95 \% \text { CI) }\end{array}$} & \multirow{2}{*}{$\begin{array}{c}\text { \% PPV } \\
(95 \% \mathrm{CI})\end{array}$} & \multirow{2}{*}{$\begin{array}{c}\text { \% NPV } \\
(95 \% \mathrm{CI})\end{array}$} \\
\hline & & $\mathbf{R}$ & $\mathbf{S}$ & Total & & & & \\
\hline \multirow{2}{*}{ DOT-BLOT } & $\mathbf{R}$ & 12 & 2 & 14 & 70.6 & 95.2 & 85.7 & 88.9 \\
\hline & $\mathbf{S}$ & 5 & 40 & 45 & $(44.0-89.7)$ & $(83.8-99.4)$ & $(57.2-98.2)$ & $(76.0-96.3)$ \\
\hline Total & & 17 & 42 & 59 & & & & \\
\hline
\end{tabular}

Table 3. Comparability between rrs gene dot-blot and phenotypic drug susceptibility testing.

\begin{tabular}{|c|c|c|c|c|c|c|c|}
\hline \multirow{2}{*}{$\begin{array}{c}\text { STREPTOMYCIN } \\
\text { (rrs gene) }\end{array}$} & \multicolumn{3}{|c|}{ Phenotypic DST, n (\%) } & \multirow{2}{*}{$\begin{array}{c}\text { \% Sensitivity } \\
(95 \% \mathrm{CI})\end{array}$} & \multirow{2}{*}{$\begin{array}{c}\% \text { specificity } \\
(95 \% \text { CI })\end{array}$} & \multirow{2}{*}{\begin{tabular}{|c|}
$\% \mathrm{PPV}$ \\
$(95 \% \mathrm{CI})$ \\
\end{tabular}} & \multirow{2}{*}{\begin{tabular}{|c|}
$\% \mathrm{NPV}$ \\
$(95 \% \mathrm{CI})$
\end{tabular}} \\
\hline & $\mathbf{R}$ & $\mathbf{S}$ & Total & & & & \\
\hline \multirow{3}{*}{ DOT-BLOT } & 25 & 2 & 27 & 92.6 & 87.5 & 92.6 & 87.5 \\
\hline & 2 & 14 & 16 & $(75.7-99.1)$ & $(61.7-98.5)$ & $(75.7-99.1)$ & $(61.6-98.5)$ \\
\hline & 16 & 0 & 16 & & & & \\
\hline Total & 32 & 27 & 59 & & & & \\
\hline
\end{tabular}

Legend: R — Resistance; S-Sensitive; UA — Unamplified; DST —Drug Susceptibility Testing; In (b) above there were 16 which did not amplify with primers to $r r s$ gene. Interestingly these come from the group that was expected to show mutations conferring resistance. Mix-in positive DNA experiments showed there were no inhibitions nor nuclease activity since the added DNA did amplify.

mutation for resistance to rifamycin (Table 2). For Streptomycin it was 2 out of the 43 (4.7\%) bacterial DNA samples that amplified (Table 3 ). Forty (67.8\%) of the samples showed both phenotypic and genotypic susceptibility to rifamycin and $14(32.6 \%)$ were both phenotypically and genotypically susceptible to streptomycin (Table 2 and Table 3). Double mutation on both the $r p o B$ and rrs genes resulting in multiple (double) resistance was found in $8(13.6 \%)$ of the samples. 
Discrepancies: Some discrepancies were identified between the phenotypic and genotypic drug pattern. False negative resistance, that is, resistance by phenotype and susceptible by genotype was found to be $8.5 \%$ in rifamycin and $4.7 \%$ in streptomycin. False positive resistance, that is, susceptible by phenotype and resistant by genotype was $3.4 \%$ in rifamycin and $4.7 \%$ in streptomycin. There was a significant difference in this discrepancies $\mathrm{p}<0.001$ to both drugs. False negative results were predominant in rifamycin while false positives were predominant in streptomycin. Mix-in experiment results demonstrate that amplification was possible in previously unamplified samples of the SM gene rrs.

\section{Discussions}

A high prevalence of drug resistant strains of Mycobacterium tuberculosis both phenotypically (28.8\% for RIF and $54.2 \%$ for SM) and genotypic resistance (23.7\% for RIF and $45.8 \%$ for SM) (Table 2 \& Table 3 ) from the South Western Cameroon is reported. We showed that the Dot-blot compared to DST had a high positive predictive value $(92.6 \%, 95 \%$ CI: 75.7 - 99.1) suggesting that the Dot-blot could be used in public health settings to establish the prevalence of mutations to TB drugs and the potential of a population to fail therapy.

Amplification was complete 59 (100\%) with rpoB (Table 2) but in only $43(72.9 \%)$ samples with rrs gene (Table 3). A mix-in experiment was performed with the 16 samples which did not amplify. It turns out that all 16 samples are complementary to the quadrant expected to show resistant mutations (Table 3). The absence of signal could not have been due to the presence of an inhibitor or nuclease as the added positive DNA did amplified with other primers. It is possible that one mechanism for Streptomycin resistance could be gene segment omissions and warrants further investigations. Double mutation on both the rpo $B$ and $r r s$ genes occurred in 8 $(13.6 \%)$ DNA samples, is indicative of multiple resistances. Mono-resistance to rifamycin is rare and its presence is indicative of multiple drug resistance (MDR) [6]. Monotherapy for streptomycin was used 50 years ago to treat tuberculosis and this monotherapy resulted to high resistance [20]. Resistance in this study was common in streptomycin than in rifamycin. This explains why the principle behind modern chemotherapy for tuberculosis lies in the association of several drugs to which the bacilli are sensitive to [21]. Females were more resistant $(52.1 \%)$ than males $(41.2 \%)$ to rifamycin while males more resistant to streptomycin $(25 \%)$ than females $(21.7 \%)$. Sex, previous treatment, age, and work type were some of the risk factors that have been reported for drug resistant TB [22] [23].

In comparing phenotypic and genotypic results, some discrepancies were noted. False positive phenotypic resistance in rifamycin (3.4\%) and streptomycin (4.7\%) occurred. False negative phenotypic resistance was predominant in rifamycin $(8.5 \%)$ than streptomycin $(4.7 \%)$. It had been found out that the routine drug resistance testing in M. tuberculosis is difficult and can sometimes give inconsistent results [6] and it is one of the most difficult technique to standardize for a diagnostic mycobacteriology laboratory due to alterations in the anti-mycobacterial activity of various drugs when incorporated into media [24]. There is therefore an urgent need to develop and make use of a high thorough put tool for detecting MDR. Considering that most drug resistant cases occur in resource poor countries [5]. Rapid detection of drug resistance could optimize treatment and improve the outcome of patients with drug resistant TB, but especially important in the prevention of transmission of drug resistant TB. It can also be used in drug surveillance studies, and will be cost-effective in resource poor countries where most MDR-TB patients reside. Drug susceptibility test is usually performed in order to provide information for the treatment of individual patients. These molecular methods cannot be used for individual patient management but can serve public health approach surveys in establishing how wide spread resistance to various drugs might be. Sensitivity testing by culture requires $3-8$ weeks and is not usually reliable. Molecular methods are designed to exploit the observation that specific mutation found in resistant strain are absent in susceptible organisms.

\section{Conclusion}

We conclude that the PCR-based dot-blot hybridization technique is comparable to the DST in establishing the resistance profile of a population to RIF. The dot blot is rapid, reproducible, not technically demanding and shortens the time of diagnosis from several weeks to two days.

\section{Limitations of the Study}

The difficulty to isolate DNA directly from sputum was a limitation. Other limitations included the fact that all 
the samples did not amplify for rrs genes, and due to the lack of MTB culture facility in the South West Region in Cameroon, sputum had to be carried all the way to the North West Region for culture and DST.

\section{Acknowledgements}

IAA was supported by the University of Buea staff development grant; VPKT was supported by the IPICS/ CAM01 Project; TMP received financial supported from the Epidemiology Research Laboratory and IAEA Grant Program RAF6040. WFM was supported by the Yaoundé University 1 grant program UYI/FS/04567Z4/ wfm/13, the RAF6040 IAEA grant and the GABRIEL Network through the AFRICARAMI EU Project and the Mezam Polyclinic tuberculosis unit.

\section{References}

[1] Bloom, B.R. and Murray, C.J. (1992) Tuberculosis: Commentary on a Re-Emergent Killer. Science, 257, $1055-1064$. http://dx.doi.org/10.1126/science.257.5073.1055

[2] Dye, C., Scheele, S., Dolin, P., Pathania, V. and Raviglione, M.C. (1999) Consensus Statement. Global Burden of Tuberculosis: Estimated Incidence, Prevalence and Mortality by Country. WHO Global Surveillance and Monitoring Project. JAMA, 282, 677-668. http://dx.doi.org/10.1001/jama.282.7.677

[3] Cohn, D.L., Bustreo, F. and Raviglione, M.C. (1997) Drug Resistant Tuberculosis: Review of the World Wide Situation and the WHO/IUATLD Global Surveillance Project. Clinical Infectious Disease, 24, 5121-5130. http://dx.doi.org/10.1093/clinids/24.Supplement 1.S121

[4] Ritacco, V., Di Lonardo, M. and Renierio, A. (1997) Spread of Human Immunodeficiency Virus-Related Multidrug Resistant Tuberculosis in Buenos Aires. Journal of Infectious Disease, 176, 637-642. http://dx.doi.org/10.1086/514084

[5] Raviglione, M.C., Snider Jr., D.E. and Kochi, A. (1995) Global Epidemiology of Tuberculosis. Morbidity and Mortality of the World Wide Epidemic. JAMA, 273, 220-226. http://dx.doi.org/10.1001/jama.1995.03520270054031

[6] Gillespie, S.H. (2002) Evolution of Drug Resistance in Mycobacterium tuberculosis: Clinical and Molecular Perspective. Antimicrobial Agents and Chemotherapy, 46, 267-274. http://dx.doi.org/10.1128/AAC.46.2.267-274.2002

[7] Ramaswamy, S.V. and Musser, J.M. (1998). Molecular Genetic Basis of Anti-Microbial Agent Resistance in Mycobacterium tuberculosis Update. Tubercle and Lung Disease, 97, 3-29. http://dx.doi.org/10.1054/tuld.1998.0002

[8] Van der Zanden, A.G., Hoentjen, A.H., Heilmann, F.G., Weltevreden, E.F., Schouls, L.M. and van Embden, J.D. (1998) Simultaneous Detection and Strain Differentiation of Mycobacterium tuberculosis Complex in Paraffin Wax Embedded Tissues and in Stained Microscopic Preparations. Molecular Pathology, 51, 209-214. http://dx.doi.org/10.1136/mp.51.4.209

[9] Githui, W.A., Jordaan, A.M., Juma, E.S., Kinyanyui, M.P., .Karimi, F.G., Kimwomi, J., Meme, H., Mumbi, M.P., Steicher, E.M., Warren, R., Van Helden, P.D. and Victor, T.V. (2004) Identification of MDR-TB Beijing/w and Other Mycobacterium tuberculosis Genotypes in Nairobi Kenya. International Journal of Tuberculosis and Lung Diseases, $\mathbf{8}$, 352-360.

[10] de Kantor, N., Kim, I., Frieden, S.J., Laszlo, T., Fluelmo, A., Norval, P.Y., Rieder, H., Valenzuela, P. and Weyer, K. (1998) Laboratory Services in Tuberculosis Control Part 11: Microscopy. WHO/TB/89.258, Jatto Associatess, Biella.

[11] Victor, T.C., Warren, R. and Butt, J.L. (1997) Genomic and MIC Stability in Mycobacterium tuberculosis and Indications for Continuation of Use of Isoniazid in Multidrug-Resistant Tuberculosis. Journal of Medical Microbiology, 46, 847-957. http://dx.doi.org/10.1099/00222615-46-10-847

[12] Meriki, H.D., Tufon, K.A., Atanga, P.N., Ane-Anyangwe, I.N., Anong, D.N., Cho-Ngwa, F. and Nkuo-Akenji, T. (2013) Drug Resistance Profiles of Mycobacterium tuberculosis Complex and Factors Associated with Drug Resistance in the Northwest and Southwest Regions of Cameroon. PLOS ONE, 8, e77410. http://dx.doi.org/10.1371/journal.pone.0077410

[13] Ratnam, S., Stead, F.A. and Howes, M. (1982) Simplified Acetylcysteine-Alkali Digestion-Decontamination Procedure for Isolation of Mycobacteria Growth Indicator Tube (MGIT) with Radiometric and Solid Culture for Recovery of Acid Fast Bacilli.

[14] Niemann, S., Richter, E. and Rüsch-Gerdes, S. (2000) Differentiation among Members of the Mycobacterium tuberculosis Complex by Molecular and Biochemical Features: Evidence for Two Pyrazinamide-Susceptible Subtypes of $M$. bovis. Journal of Clinical Microbiology, 38, 152-157.

[15] Canetti, G., Fox, W. and Khomenko, A. (1969) Advances in Techniques of Testing Mycobacterial Drug Sensitivity, and the Use of Sensitivity Tests in Tuberculosis Control Programmes. Bull World Health Organ, 41, 21-43.

[16] Nolt, F.S., Metchock, B., McGowan, J.E., Edwads Jr., A., Okwumabua, O., Thurmond, C., Mitchell, S., Plikaytis, B. 
and Shinnick, T. (1993) Direct Detection of Mycobacterium tuberculosis in Sputum by Polymerase Chain Reaction and DNA Hybridization. Journal of Clinical Microbiology, 31, 1777-1782.

[17] Victor, T., du Troit, R., Jordan, A.M. and Bester Van Helden, P.D. (1990) No Evidence for Point Mutation on Codon 12-13, and 61 of the ras Gene in a High-Incidence Area for Osophageal and Gastric Cancer. Cancer Research, 50, 4911.

[18] World Health Organization (1991) Tuberculosis Surveillance and Monitoring. Report of a WHO Workshop. World Health Organization, Geneva.

[19] Mitchison, D.A. (1950) Development of Streptomycine Resistant Strains of Tubercle Bacilli in Pulmonary Tuberculosis: Results of Simultaneous Sensitivity Test in Liquid and Solid Media. Thorax, 5, 144-161.

[20] Nunes, E.A., De Capitani, E.M., Coelho, E., Joaquim, A.O., Figueiredo, I.R.O., Cossa, A.M., Panunto, M. and Carvalho-Ramos. Patterns of Anti-Tuberculosis Drug Resistance among HIV-Infected Patients in Moputo, Mozambique, 2002-2003. International Journal of Tuberculosis and Lung Disease, 9, 494-500.

[21] Kuaban, C., Bersion, R., Jifon, G., Cunin, P. and Blackett, N.T. (2000) Acquired Anti-Tuberculosis Drug Resistance in Yaoundé, Cameroon. International Journal of Tuberculosis and Lung Diseases, 4, 427-432.

[22] Annie, L. and Vestal, B.S. (1975) Procedures for the Isolation and Identification of Mycobacteria. CDC Publication, 81, 97.

[23] Vashakidze, L., Salakaia, A., Shubladze, N., Cynamon, M., Barbakadze, K., Kikvidze, M., Papitashvili, L., Nonikashvili, M., Solomonia, N., Bejanishvili, N. and Khurtsilava, I. (2009) Prevalence and Risk Factors for Drug Resistance among Hospitalized TB Patients in Georgia. International Journal of Tubercle and Lung Disease, 13, 1148-1153.

[24] Kim, S.J. (2005) Drug-Susceptibility Testing in Tuberculosis: Methods and Reliability of Results. European Respiratory Journal, 25, 564-569. 